\title{
Respuesta a los comentarios
}

\author{
Eduardo Crespo SuÁrez

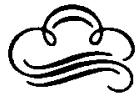

Amalio Blanco plantea una cuestión que me parece importante, la referida a la dualidad implícita tanto en el concepto de actitud como en las teorías que pretenden explicar el cambio de actitud en base a presupuestos más o menos racionalistas. Esta dualidad, si he entendido bien, consiste en el mantenimiento simultáneo de una hipótesis sobre el carácter racional, conforme a las leyes de la lógica formal, de la solución de conflictos cognitivos, a la vez que una propuesta sobre el carácter motivacional de lo cognitivo y, por tanto, de la búsqueda de coherencia cognitiva; motivación cuyos resultados pueden ser irracionales por ilógicos. Sería la dualidad entre el pensamiento lógico y el pensamiento de deseos. Sobre este asunto yo creo, por una parte, que la dualidad a la que Blanco hace referencia no es una cuestión exclusiva de las teorías sobre las actitudes sino que es expresión de una ambigüedad y contradicción existente en el pensamiento común occidental sobre la estructura del pensamiento; en cierto modo es una herencia del pensamiento cartesiano y racionalista. Por otra parte, creo que algunas de las teorías cognitivas sobre el cambio de actitud a las que $\mathrm{A}$. Blanco menciona parten de una conciencia de dicha dualidad, a la que se enfrentan en términos psicológicos. Finalmente, creo que una posible salida a la paradoja planteada consiste en situar en un espacio social y no psicológico su dinámica, abordando la racionalidad en términos de pragmática y de retórica y no en los de la lógica formal.

La dualidad inherente al concepto de actitud es posible entenderla si adoptamos una actitud construccionista y consideramos que los objetos de investigación de las ciencias sociales son histórica y socialmente construidos. El concepto de actitud, así como los de creencia y opinión relacionados con él, es heredero de las teorías cotidianas sobre la estructura del pensamiento y la afectividad, en cuya génesis ocupan un lugar importante las teorías científicas y filosóficas que, por difusión o por efecto de ilustración, contribuyen a configurar un vocabulario de referencia. En el caso de la opinión y de las actitudes, así como en la mayoría de los conceptos mentales, el vocabulario de las principales lenguas occidentales, con el cual se han elaborado estas teorías, se estabiliza en el siglo XVIII cuando se difunde el pensamiento racionalista. Mientras que en el siglo XVII se da todavía una cierta superposición de los campos semánticos afectivo y cognitivo, ese solapamiento desaparece ya en los vocabularios del siglo XVIII (1). La dualidad a la que hace referencia A. Blanco es, en realidad, la dualidad cartesiana que, ajena a toda consideración dialógica, situó a la psicología científica ante la paradoja de que la única posibilidad de un conocimiento cien- 
tífico de la mente pasara por su negación. Lo que he intentado en el artículo anterior es poner de manifiesto que esta dualidad es posible abordarla de otro modo cuando se adopta una posición interaccionista y no psicologista.

Por ello, he considerado la evaluación no como respuesta psicológica, afectiva y emocional, sino como momento de la acción, susceptible por tanto de crítica. [La necesidad de coherencia cognitiva sería así comprensible en términos de legitimación y justificación, que es un proceso social, más que en términos de motivación, como la propia investigación sobre disonancia puso de manifiesto (Gerard, Conolley y Wilhelmy, 1974, por ejemplo).]

La dualidad conceptual a la que $\mathrm{A}$. Blanco hace referencia creo que fue la que llevó a Festinger (1975) a hablar de psicológica y no de lógica formal a propósito de la teoría de la disonancia. Para Festinger las cogniciones disonantes lo eran no sólo en virtud de una contradicción conforme a la lógica formal, sino en general, en tanto fuesen consideradas como incoherentes por el sujeto. Las convenciones culturales o las experiencias pasadas eran también consideradas fuentes potenciales de disonancia. De hecho, Aronson (1968), consideró que la disonancia se podía generar por la violación de alguna expectativa. Esta psicologización de la lógica fue una de las razones que llevó, en mi opinión, al callejón sin salida en que se encontró la teoría de la disonancia en los años 70 . La psico-lógica es, casi por definición, inabordable en términos públicos, como lo son los tratamientos experimentales; la equivalencia de tratamiento no puede asegurar la equivalencia de estado (consonancia/disonancia: hecho interno y privado), de forma que todo dato que no confirme las hipótesis previstas es reinterpretable siempre en función de otras variables intervinientes (autoconcepto, compromiso, justificación resultante...), y así es como ocurrió. En mi opinión, creo que podría entenderse la contradicción cognitiva no en términos de la lógica formal o de la psico-lógica, sino en lo que podría denominarse socio-lógica (2), cuya dinámica y validación es pública, y cuyos procesos son semióticos. Por eso tiene sentido, en mi opinión, hablar de racionalidad, no en el sentido de adecuación a los cánones ahistóricos y permanentes de la lógica formal, sino en términos de autoridad intelectual y legitimación en un medio social, históricamente constituido, en «los nichos reales dentro de los cuales se hacen en la práctica evaluaciones racionales» (Toulmin 1977: 44).

Antaki plantea, por su parte, la debilidad del vínculo que establezco entre actitudes y racionalidad. Estoy de acuerdo con él en que eso es cierto si se basa en una visión histórica de lo que ha sido dominante en el estudio de las actitudes. Pero mi pretensión era otra; no se trata de ser caritativo con los teóricos de las actitudes, como él dice. Simplemente constato que es ésta una tradición de investigación que no es trivial (apunta a problemas sociales importantes) y que es plural. Mi pretensión no es en absoluto escolástica, reinvindicar una escuela o algo por el estilo. En realidad, pretendía simplemente explorar la productividad del concepto de racionalidad a propósito de los problemas a los que se ha intentado responder con una teorización actitudinal. Por eso me fijé en la evaluación. Ciertamente, y así lo señalo en el artículo, el sentido de la evaluación es muy corto en muchos modelos y teorías, pero no tiene por qué necesariamente entenderse así. Puede que Antaki tenga razón cuando plantea -como Potter y Wetherell - que lo mejor es abandonar la teoría de actitudes; lo que ocurre es que, por una parte, las propuestas teóricas alternativas no me parecen teóricamente más consistentes, y por otra, en la teoría de las actitudes hay propuestas que nos permiten entender éstas desde un punto de vista interactivo 
y no necesariamente identitario, como propiedades «internas» del sujeto. Por eso, mi posición respecto al uso de cuestionarios es más tolerante que la de Antaki. Si se entienden como elementos de una interacción social, los cuestionarios pueden ser $-\mathrm{y}$ de hecho lo son- herramientas importantes para el conocimiento de una realidad social, que no de las «verdaderas» actitudes.

Tiene razón Antaki al decir que se da un salto no justificado desde la evaluación de un objeto a la evaluación del actor. Creo, sin embargo, que ese salto resulta más legítimo si se entiende en términos interactivos. La evaluación de un objeto es parte de un proceso, al menos potencialmente, comunicativo y discursivo. La acción humana, en tanto no se entienda como conducta autonómica, incompetente, distraída o impulsiva, está abierta a la justificación. Pero no sólo la acción sino también los sentimientos serían susceptibles de justificación, como sugiere Toulmin (1974). Considera este autor que el gusto/disgusto por algo o alguien puede tener dos sentidos, el de objeción y el de aversión. El primero, el «tener que objetar», es un comportamiento aprendido, mientras que la aversión la considera una conducta autonómica. Esta distinción es de utilidad para nuestra disquisición. El concepto de objeción es muy similar, en realidad, al de evaluación actitudinal en el sentido que le vengo dando. Para Toulmin, se puede dar cuenta tanto de la aversión como de la objeción en términos de las razones por las que, mientras que sólo se pueden dar razones para la objeción. Este segundo tipo de razones es el que implica, en su opinión, el uso de argumentaciones y el recurso a procederes racionales. Podríamos, pues, considerar que nuestras evaluaciones son evaluables, en tanto forman parte de una red social de significados, y no sólo de la esfera personal de reacciones afectivas. La actitud, desde este punto de vista, está más vinculada a la acción que a la vivencia subjetiva.

M. D. Avia considera adecuada, desde su punto de vista, una explicación de la actividad terapéutica en términos de acción comunicativa más que de persuasión. El problema se le plantea al hablar de racionalidad, lo que le lleva a preguntar qué se entiende por racionalidad y, en definitiva, a considerar el carácter predominantemente no racional de los procesos de formación y cambio de actitudes. Su comentario me fuerza a precisar algo más el sentido en que he utilizado en el artículo el concepto de racionalidad.

En primer lugar, he de indicar que el objeto de mi reflexión no es la descripción de una realidad psicológica en términos de racionalidad/irracionalidad -o razón/emoción, etc. - sino la del modelo de acción con el que trabajan muchas de las teorías existentes sobre la formación y cambio de actitud. Planteado en el terreno de la adecuación individual con estándares, clínicos o psicológicos, una reflexión sobre la racionalidad es posible que derive a una discusión meramente formal que creo que no tiene interés. Respecto al sentido de la racionalidad, mi pretensión — no sé si lograda - era utilizar el concepto de racionalidad en un sentido social y no exclusivamente individual. Bien es cierto que el sentido más usual, incluso en sociología, cuando se habla, por ejemplo, del «rational choice», o en la propia psicología social, con la teoría de la acción razonada, hace referencia a un proceso individual, pero creo igualmente que es teóricamente productivo relacionar el concepto de racionalidad con los procesos públicos de legitimación. Desde mi punto de vista, la racionalidad puede entenderse como la posibilidad de dar razón de la propia acción y de las actitudes, consideradas como elementos de ésta. El sujeto es, en este sentido, parte integrante del proceso de creación y negociación de los estándares evaluativos. La racionali- 
dad se manifiesta entonces como argumentabilidad o, dicho de otro modo, la racionalidad se desarrolla de modo pragmático y retórico.

La racionalidad se suele identificar, desde el punto de vista del pensamiento, con la adecuación a la lógica formal y, desde el punto de vista de la acción, con la eficacia. El máximo exponente del saber claro y distinto era para Descartes la geometría. La matematización se ha convertido posteriormente en el objetivo de todo saber que se pretenda científico y racional. Sin embargo, existe una tradición de pensamiento en la que se considera legítimo hablar de racionalidad no sólo respecto a los procesos lógicos sino también en relación con los procesos retóricos. La retórica es entendida aquí en su sentido clásico, no sólo como arte de la persuasión sino, en general, como saber argumentativo. Un enfoque retórico llama la atención sobre las prácticas discursivas, tanto cotidianas como científicas (Simons, 1989). El enfoque retórico implica una descripción intrínsecamente plural de la vida social. A diferencia de un enfoque lógico, unívoco, el enfoque retórico pone de manifiesto el carácter plural (básicamente dual: pro y contra, como señala Billig, 1987) de toda manifestación del pensamiento, y por tanto su carácter ambiguo y analógico.

La racionalidad argumentativa se fundamenta en una filosofía sin metafísica (Meyer, 1989), en un método no cartesiano, donde la razón no se vincula exclusivamente con la evidencia, y para la que el desacuerdo no es un signo de error, ya que el modelo de razonamiento lo constituye el debate y no la geometría. La razón no se reduce, desde un punto de vista retórico, a una mera capacidad de cálculo, puesto que, como dicen Perelman y Olbrechts-Tyteca (1989: 1), «la naturaleza misma de la deliberación y la argumentación se opone a la necesidad y a la evidencia, ya que no se delibera allí donde la solución es necesaria, así como no se argumenta contra la evidencia». Desde este punto de vista, la racionalidad se encuentra vinculada con la apertura a lo múltiple y a lo no forzado. Es ésta, justamente, la perspectiva que pretendía recuperar para la teoría de actitudes.

Esta racionalidad tolerante, abierta a la diversidad, no es sólo una característica del saber cotidiano, sino también del saber científico social. La evidencia incontrovertible no es la única fundamentación empírica posible para las ciencias sociales. Tal vez no lo sea siquiera nunca, como se ha puesto de manifiesto a propósito de los experimentos cruciales. Lo que pretendo plantear es que la admisión de la ambigüedad de significación no deja de ser un modo de fundamentación empírica ni es un territorio propio de la arbitrariedad y la irracionalidad, al menos en el sentido en que la he considerado. M. D. Avia se refiere a la teoría de la atribución. Creo que es un buen ejemplo, pero no por las disquisiciones sobre el carácter razonable o no de las atribuciones, lo que nos lleva al viejo problema de los sesgos, sino por su posible comprensión en términos de acción y de argumentación.

Finalmente, creo que es pertinente hablar de racionalidad porque creo que existe una cierta relación entre racionalidad y violencia. En los últimos años se ha puesto de manifiesto la relación entre una concepción absolutista de la racionalidad y el ejercicio de la violencia. Los efectos devastadores de las concepciones totalizantes de la racionalidad y su concomitante idea sobre el progreso, tanto sea económico-industrial como político, son evidentes. No es por ello extraño que se plantee una concepción plural y no dogmática de la racionalidad, como es la de la retórica. Perelman y Olbrech-Titeca señalan, justamente, cómo el interés por la retórica aparece históricamente en aquellas épocas en que se ha perdido la confianza en el mito. 


\section{Notas}

1. Según Dumonceaux (1975), en Francia, en el siglo xvil, la palabra «sentiment» era muy cercana en su significado a «opinión» y «avis». El «sentiment» no surge de una fuente propiamente afectiva, en el sentido actual, sino que «expresa de manera inmediata y sin ambigüedad una manera de ver las cosas estrechamente personal, que se traduce a menudo por una toma de posición personal» (p. 448). En un sentido muy similar utiliza el término castellano «sentimiento" Jerónimo de Barrionuevo en sus famosos Avisos de 1656.

2. En un sentido similar al aquí utilizado, Uli Windisch $(1982,1990)$ habla de una pluralidad de formas lógico-discursivas, caracterizadoras de diferentes estructuras socio-cognitivas.

\section{Referencias}

Aronson, E. (1968) Dissonance Theory: progress and problems. En R. P. Abelson y otros (eds.) Theories of cognitive consistency: a sourcebook. Chicago: Rand McNally.

Barrionuevo, J. (1956) Avisos. Madrid: B.A.E. Vol. 221.

Billig, M. (1987) Arguing and thinking. A rethorical approach to social psychology. Cambrid. ge Univ. Press.

DumONCEAUX. P. (1975) Langue et sensibilité au XVIIle. siécle. L'évolution du vocabulaire affectif. Genève: Droz.

Festinger, L. (1975) Teoría de la disonancia cognoscitiva Madrid:Instituto de Estudios políticos.

Gerard, H. B., Conolley, E. S. y Wilhelmy, R. A. (1974) Compliance, justification and cognitive change. En Berkowitz (ed.) Advances in experimental social psychology vol. $7 . \mathrm{N}$. York: Academis Press.

Meyer, N. (1989) Preface. En C. Perelman y L. Olbrechts-Tyteca.

Perelman, C. y Olbrechts.Tyteca, L. (1989) Traité de l'Argumentation. Bruxelles: Editions de l'Université de Bruxelles. (5.' edic.).

SimONs, H. W. (1989) Rbetoric in the human sciences. London: SAGE.

Toulmin, S. (1974) Razones y causas. En N. Chomsky y otros La explicación en las ciencias de la conducta. Madrid: Alianza Universidad.

Toulmin, S. (1977) La comprensión bumana. 1. El uso colectivo y la evolución de los conceptos. Madrid:Alianza Ed.

EINDISCH. U. (1982) Pensée sociale, langage en usage et logiques autres. Lausanne: Editions L'Age d'Homme.

WINDISCH, U. (1990) Speech and reasoning in everyday life. Cambridge: Cambridge University Press. 